\title{
Formas e épocas de amostragem em folhas de pinhão manso para quantificação da área foliar
}

\author{
Pollione Martins dos Santos ${ }^{1}$, Rodrigo Ribeiro Fidelis ${ }^{*}$, Joseanny Cardoso da Silva \\ Pereira $^{1}$, Eduardo Andréa Lemus Erasmo ${ }^{1}$, Hélio Bandeira Barros ${ }^{1}$ e Glauber Lacerda de \\ Carvalho
}

${ }^{1}$ Departamento de Agronomia; Universidade Federal do Tocantins; 77402-970; Gurupi - TO - Brasil.

\begin{abstract}
This work aimed to determine the ideal leaf size, and also in which position of the plant such measurements must be processed in Jatropha curcas. The experiment was carried out at the Federal University of Tocantins in a randomized complete block design with 24 treatments and 6 replicates. A method based on leaf length and leaf width was used to determine total leaf area. The results showed that total leaf area was underestimated when only small leaves were sampled. On the other hand, total leaf area was overestimated when only large leaves were sampled. It shows that the measurement of large and medium leaves at the upper and middle of the plant can be used to determine total leaf area. We therefore conclude that sampling forms is determined by the period of measurement; the fourth period of measurement is the most indicated to quantify the width of Jatropha curcas leaves; and to the measurement of total leaf area, the upper side of the plant was the best place of sampling.
\end{abstract}

Key words: Jatropha curcas L., leaf area, non-destrultive methodology

\section{INTRODUÇÃO}

O pinhão manso (Jatropha curcas L.) é uma planta conhecida e cultivada há vários anos, mas ainda encontra-se em processo de domesticação e somente nos últimos anos começou a ser pesquisado de forma mais intensa (Avelar et al., 2006).

É uma planta perene da família euforbiácea e pode atingir de 3 a $12 \mathrm{~m}$ de altura. Entre as oleaginosas, é considerada uma das favoritas para a produção de combustível alternativo, o biodiesel (Nunes et al., 2006). Além disso, o óleo é também usado para a fabricação de sabão e como purgativo para o gado bovino como também na indústria de tintas e vernizes, a casca pode ser usada como carvão vegetal e matéria prima na fabricação de papel, etc. Esta espécie é resistente à seca e é frequentemente cultivada em países tropicais como cerca - viva; muitas partes da planta são utilizadas como remédio na medicina popular, no entanto, as sementes são tóxicas a humanos e muitos outros animais (Heller, 1996).

A área foliar de uma planta depende do número e do tamanho das folhas, bem como do seu tempo de permanência na planta (Monteiro et al., 2005). A determinação da área foliar da planta é uma importante ação que permite ao pesquisador obter indicativo de resposta de tratamentos aplicados e lidar com uma variável que se relaciona diretamente com a capacidade fotossintética e de interceptação da luz, além de interferir na cobertura do solo, na competição com outras plantas e em várias características (Severino et al., 2004). Assim, a superfície foliar de uma planta é à base do rendimento potencial da cultura (Favarin et al., 2002).

São vários os métodos destrutivos e não destrutivos utilizados para a determinação da área foliar (Benincasa, 1988). A escolha de um ou de outro método depende, principalmente, da quantidade de material vegetal e dos equipamentos disponíveis. Alguns métodos, como o do planímetro, pesagem de discos e cópias xérox demandam muito tempo, bem como a destruição do material, o que inviabiliza sua utilização no nível de campo. Os métodos não destrutivos, com a utilização de aparelhos portáteis, embora eficazes e práticos, têm uso restrito, uma vez que

Author for correspondence: fidelisrr@uft.edu.br

J. Biotec. Biodivers. v. 2, N.3: pp. 51-57, Aug. 2011 
os aparelhos apresentam um elevado custo de aquisição (Oliveira et al., 2002).

Sendo assim, a determinação da área foliar por um método simples e rápido, de baixo custo operacional e, principalmente, não destrutivo, torna-se de grande importância quando se pretende realizar uma análise quantitativa do crescimento das plantas. Para a determinação da taxa de crescimento das folhas, por exemplo, o método de determinação da área foliar, através de suas dimensões lineares, é bastante satisfatório, visto não requerer destruição do material, ser relativamente rápido, de baixo custo, além de poder ser facilmente utilizado em condições de campo. Vários autores têm obtido coeficientes de correlação bastante elevados e equações que relacionam dimensões lineares das folhas, como o comprimento, a largura ou o produto destes com a área foliar, com um alto grau de precisão (Oliveira et al., 2002).

Estudos que apontem quais as folhas devem ser amostradas, o melhor local para efetuar esta amostragem visando uma medição segura e que represente a área foliar real total mensurada são importantes e necessários à cultura do pinhão manso, o que facilitaria a adoção de ações que permitam ao pesquisador obter indicativo de resposta de tratamentos aplicados, ou seja, na determinação da área foliar.

Desta forma, este trabalho objetivou avaliar o tamanho ideal de folhas e em que local da planta devem ser realizadas medições, utilizando-se de uma metodologia não destrutiva para a determinação da área foliar total de pinhão manso.

\section{MATERIAL E MÉTODOS}

$\mathrm{O}$ experimento foi conduzido na estação experimental da Universidade Federal do Tocantins (UFT), em Gurupi - TO, com coordenadas geográficas de latitude de $11^{\circ} 43^{\prime} \mathrm{S}$, longitude de $49^{\circ} 04^{\prime} \mathrm{N}$ e altitude de $280 \mathrm{~m}$ em Latossolo Vermelho Amarelo Distrófico.

As mudas de pinhão manso foram cedidas pela Cooperativa de Orlândia e tinham aproximadamente 60 dias de germinadas. Foi utilizado o sistema de plantio convencional com uma aração e duas gradagens, além do sulcamento do terreno. O plantio das mudas foi realizado manualmente, no dia 26 de dezembro de 2006. O espaçamento utilizado foi o de $2 \mathrm{~m}$ entre plantas e $3 \mathrm{~m}$ entre linhas. A calagem e a adubação de plantio foram realizadas seguindo as recomendações da análise química e física do solo. Assim, aplicou-se no plantio $200 \mathrm{~g} /$ cova de calcário dolomítico e 400g/cova de superfosfato simples. Realizaram-se ainda quatro adubações de cobertura, cada uma com $15 \mathrm{~g} /$ cova da formulação 20-0-20 de NPK (sendo a primeira realizada no dia $15 / 01$, a segunda $16 / 02$, a terceira $16 / 03$ e última $16 / 04$ de 2007). Os tratos culturais foram realizados sempre que necessários. Cada unidade experimental foi constituída por uma planta de pinhão manso que se encontrava próximo do estágio de florescimento (180 dias após emergência).

Foi adotado o delineamento experimental inteiramente casualizado para realização dos testes, com 24 tratamentos e seis repetições. Os tratamentos foram dispostos em esquema fatorial (6 x 4), constituído por seis formas de se amostrar a planta [1 - forma de amostragem tida como padrão onde se mensura todas as folhas grandes (a partir de $10 \mathrm{~cm}$ de comprimento por 12 de largura) e médias da planta inteira (a partir de $4,5 \mathrm{~cm}$ comprimento por 6,0 de largura); 2 - somente as folhas grandes da planta inteira; 3 - somente as folhas médias da planta inteira; 4 - folhas grandes e médias do terço inferior da planta; 5 - folhas grandes e médias do terço médio da planta; e 6 folhas grandes e médias do terço superior da planta] e quatro épocas de mensuração (I - 118, II - 138, III - 158 e IV - 178 dias após o transplante das mudas).

Pelo fato de ainda não se conhecer variedades melhoradas ou cultivares de pinhão manso (Saturnino et al., 2005), a plantação onde se realizou o estudo foi confeccionada por meio de uma mistura de plantas com descendência genética diferente, o que implica numa lavoura desuniforme com plantas variando no tamanho, diâmetro de colmo, número e disposição dos ramos, etc. Desta forma, visando minimizar o efeito da diferença genética, tomaram-se alguns cuidados na escolha das plantas a serem mensuradas, dando preferência àquelas plantas que apresentavam alguma semelhança, como altura, número e disposição de ramos. A Figura 1 ilustra as plantas selecionadas apresentando três ramos (formando um tridente), sendo um central e dois opostos. 


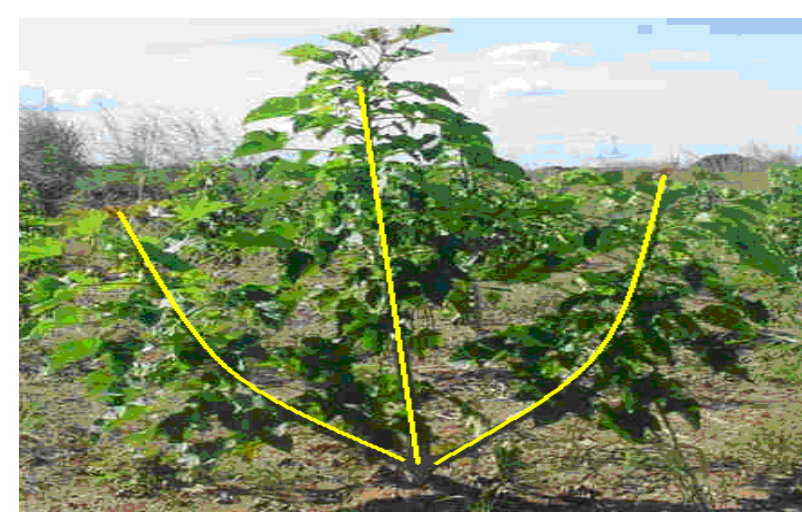

Figura 1 - Planta de pinhão manso contendo três ramos (sendo um considerado o principal e dois secundários e opostos) formando um tridente.

Diversas metodologias utilizam-se da medição das dimensões comprimento (C) e largura (L) das folhas para quantificação da área foliar. Onde o comprimento é definido como a distância entre o ponto de inserção do pecíolo no limbo foliar e a extremidade oposta da folha e a largura como a maior dimensão perpendicular ao eixo do comprimento (Monteiro et al., 2005), obtidos com o auxílio de uma régua milimetrada, conforme mostra a Figura 2.

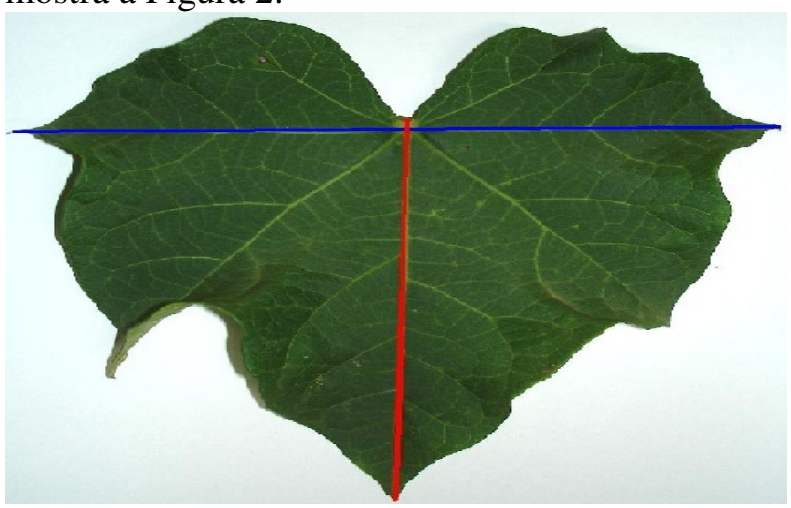

Figura 2 - Medidas lineares obtidas nas folhas do pinhão manso: nervura principal (linha vermelha) e largura (linha azul).
Severino et al. (2006), testaram nove modelos teóricos baseado nessas duas medidas, utilizando modelos lineares, quadráticos e exponenciais e concluíram que a fórmula $\left(\mathrm{A}=0,84(\mathrm{P} \times \mathrm{L})^{0,99}\right)$ apresentou alto coeficiente de determinação e boa estabilidade para medição de folhas pequenas, médias e grandes de pinhão manso.

Desta forma e considerando o trabalho supracitado, preconizou-se que estas medidas (comprimento e largura) estão diretamente relacionadas com área foliar.

As análises estatísticas foram realizadas segundo os métodos convencionais, as variáveis foram submetidas à análise de variância pelo teste ' $F$ ' e para as comparações entre as médias foi utilizado o teste de Tukey ambos ao nível de 5\% de probabilidade para testar a significância dos tratamentos, utilizando-se o programa estatístico SISVAR.

\section{RESULTADOS E DISCUSSÃO}

Foi observado através da análise de variância, que houve significância da interação para as características comprimento da nervura principal, largura das folhas e área foliar do pinhão manso, indicando comportamento diferenciado das formas de amostragem das plantas nas diferentes épocas de mensuração (Tabela 1). Assim sendo, foram realizados os desdobramentos.

Tabela 1. Análise de variância das características comprimento, largura e área foliar de pinhão manso em seis formas de amostragem das plantas (FAP) e quatro épocas de mensuração (EM), em Gurupi-TO.

\begin{tabular}{lcccc}
\hline \multirow{2}{*}{ Fonte de variação } & GL & Comprimento & Largura & Área foliar \\
\cline { 2 - 5 } Repetições & 5 & $4856,4833^{\mathrm{ns}}$ & $14865,2778^{\mathrm{ns}}$ & $2020168,1236^{\mathrm{ns}}$ \\
FAP & 5 & $646681,3167^{*}$ & $1157546,0111^{*}$ & $219204632,29^{*}$ \\
EM & 3 & $48074,8611^{*}$ & $140462,2963^{*}$ & $19803147,822^{*}$ \\
FAP X EM & 15 & $7297,4611^{*}$ & $32422,0407 *$ & $3296720,0051^{*}$ \\
Resíduo & 115 & 4021,3065 & 11919,9705 & 1621031,29463 \\
\hline \multicolumn{1}{c}{ C.V. $(\%)$} & \multicolumn{5}{c}{1,05} \\
\hline
\end{tabular}

* Significativo a $5 \%$ de probabilidade pelo teste $\mathrm{F}$. 
Com base nos resultados obtidos na análise de variância, observa-se que os coeficientes de variação para as características comprimento, largura das folhas e área foliar foram baixos, indicando a alta precisão experimental alcançada e refletindo o sucesso na tentativa de uniformização das plantas.

Para que as interpretações dos dados envolvendo formas de amostragem das plantas sejam efetuadas de forma correta, deve-se tomar o cuidado de comparar todas as formas de amostragem com a forma tida como tratamento padrão, onde se mensurou folhas grandes e médias da planta inteira. Para comprimento da nervura principal e largura das folhas de pinhão manso, as maiores médias (11,96 e 13,35, respectivamente) resultaram da forma de amostragem em que se mensurou folhas grandes da planta inteira, independente da época de mensuração (Tabela 2 e 3). Similarmente, as menores médias $(6,91$ e 6,56 , respectivamente) resultaram da forma de amostragem onde se mensurou folhas médias da planta inteira, independente da época de mensuração.

Tabela 2. Médias de comprimento da nervura principal da folha $(\mathrm{cm})$, em seis formas de amostragem das plantas de pinhão manso e quatro épocas de mensuração, na safra 2007, em Gurupi-TO.

\begin{tabular}{|c|c|c|c|c|c|}
\hline \multirow{2}{*}{$\begin{array}{c}\text { Formas de amostragem das } \\
\text { plantas }\end{array}$} & \multicolumn{4}{|c|}{ Época de mensuração } & \multirow[t]{2}{*}{ Média } \\
\hline & I & II & III & IV & \\
\hline $\begin{array}{llll}\text { Folhas grandes e médias da } \\
\text { planta inteira }\end{array}$ & $9,04 \mathrm{Ba}$ & $9,00 \mathrm{BCa}$ & $8,72 \mathrm{Ba}$ & $8,59 \mathrm{Ba}$ & 8,84 \\
\hline Folhas grandes da planta inteira & $12,18 \mathrm{Aa}$ & $12,21 \mathrm{Aa}$ & $11,85 \mathrm{Aa}$ & $11,59 \mathrm{Aa}$ & 11,96 \\
\hline Folhas médias da planta inteira & $6,86 \mathrm{Ca}$ & 6,90 Da & $6,98 \mathrm{Ca}$ & 6,91 Ca & 6,91 \\
\hline $\begin{array}{l}\text { Folhas grandes e médias do terço } \\
\text { inferior da planta }\end{array}$ & $9,17 \mathrm{Ba}$ & $9,70 \mathrm{Ba}$ & $8,78 \mathrm{Ba}$ & 7,72 $\mathrm{BCb}$ & 8,84 \\
\hline $\begin{array}{l}\text { Folhas grandes e médias do terço } \\
\text { médio da planta }\end{array}$ & $9,43 \mathrm{Ba}$ & $8,87 \mathrm{BCab}$ & $8,76 \mathrm{Bab}$ & $8,38 \mathrm{Bb}$ & 8,86 \\
\hline $\begin{array}{l}\text { Folhas grandes e médias do terço } \\
\text { superior da planta }\end{array}$ & $9,26 \mathrm{Ba}$ & $8,52 \mathrm{Cab}$ & $8,03 \mathrm{BCb}$ & $7,90 \mathrm{BCb}$ & 8,43 \\
\hline Média & 9,32 & 9,20 & 8,85 & 8,52 & 8,97 \\
\hline
\end{tabular}

${ }^{1 /}$ Médias seguidas por uma mesma letra maiúscula na coluna e minúscula na linha não diferem entre si, ao nível de $5 \%$ de probabilidade, pelo teste Tukey.

Tabela 3. Médias de largura da folha $(\mathrm{cm})$, em seis formas de amostragem das plantas de pinhão manso e quatro épocas de mensuração, na safra 2007, em Gurupi-TO.

\begin{tabular}{|c|c|c|c|c|c|}
\hline \multirow{2}{*}{$\begin{array}{c}\text { Formas de amostragem das } \\
\text { plantas }\end{array}$} & \multicolumn{4}{|c|}{ Época de mensuração } & \multirow[t]{2}{*}{ Média } \\
\hline & I & II & III & IV & \\
\hline $\begin{array}{l}\text { Folhas grandes e médias da } \\
\text { planta inteira }\end{array}$ & $9,30 \mathrm{Ba}$ & $9,65 \mathrm{BCa}$ & $9,06 \mathrm{Ba}$ & $8,83 \mathrm{Ba}$ & 9,21 \\
\hline $\begin{array}{l}\text { Folhas grandes da planta } \\
\text { inteira }\end{array}$ & $14,20 \mathrm{Aa}$ & 13,80 Aab & $13,17 \mathrm{Aab}$ & $12,24 \mathrm{Ab}$ & 13,35 \\
\hline $\begin{array}{l}\text { Folhas médias da planta } \\
\text { inteira }\end{array}$ & $6,03 \mathrm{Ca}$ & 6,54 Da & 6,85 Ca & 6,80 Ca & 6,56 \\
\hline $\begin{array}{l}\text { Folhas grandes e médias do } \\
\text { terço inferior da planta }\end{array}$ & $10,29 \mathrm{Bab}$ & $10,79 \mathrm{Ba}$ & $8,94 \mathrm{Bb}$ & 6,68 Cc & 9,18 \\
\hline $\begin{array}{l}\text { Folhas grandes e médias do } \\
\text { terço médio da planta }\end{array}$ & $10,24 \mathrm{Ba}$ & $9,70 \mathrm{BCa}$ & $9,60 \mathrm{Ba}$ & 8,75 Ba & 9,57 \\
\hline $\begin{array}{l}\text { Folhas grandes e médias do } \\
\text { terço superior da planta }\end{array}$ & $9,56 \mathrm{Ba}$ & $8,96 \mathrm{Ca}$ & $8,57 \mathrm{BCa}$ & $8,30 \mathrm{BCa}$ & 8,85 \\
\hline
\end{tabular}
terço superior da planta

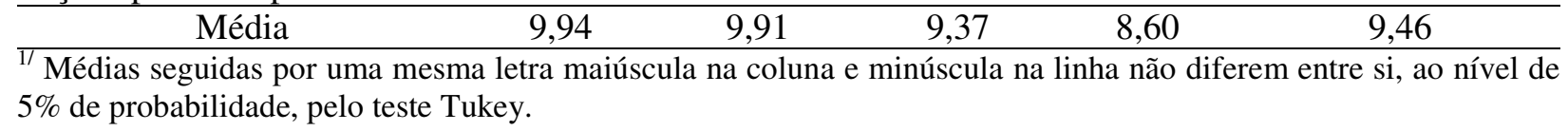

Desta forma, nota-se que a amostragem feita nas folhas grandes da planta inteira não é a mais indicada para quantificar a área foliar desta cultura, já que apresenta média superior a forma de 
amostragem tida como padrão para comparação (Tabela 4). A utilização desta forma de amostragem resultaria na superestimação da área foliar (35\% a mais para comprimento e $45 \%$ a mais para largura), em relação à forma de amostragem tida como padrão, gerando dados imprecisos conforme pode ser visto na Tabela 5, respectivamente. Semelhantemente, o tratamento em que se amostraram somente folhas médias da planta inteira também não é recomendado, já que se mostrou inferior à forma de amostragem tida como padrão e adotá-la significaria subestimar a área foliar da planta $(20 \%$ a menos para comprimento e $29 \%$ a menos para largura), resultando em leituras não confiáveis.

Tabela 4. Médias de área foliar $(\mathrm{cm})$, em seis formas de amostragem das plantas de pinhão manso e quatro épocas de mensuração, na safra 2007, em Gurupi-TO.

\begin{tabular}{llccccc}
\hline \multirow{2}{*}{$\begin{array}{l}\text { Formas de amostragem das } \\
\text { plantas }\end{array}$} & \multicolumn{5}{c}{ Época de mensuração } & \multirow{2}{*}{ Média } \\
\cline { 2 - 6 } & I & II & III & IV & \\
\hline $\begin{array}{l}\text { Folhas grandes e médias da } \\
\text { planta inteira }\end{array}$ & $6776,0 \mathrm{Ba}$ & $7011,5 \mathrm{BCa}$ & $6418,8 \mathrm{Ba}$ & $6178,5 \mathrm{Ba}$ & 6596,2 \\
$\begin{array}{l}\text { Folhas grandes da planta } \\
\text { inteira }\end{array}$ & $13810,7 \mathrm{Aa}$ & $13481,8 \mathrm{Aa}$ & $12477,8 \mathrm{Aab}$ & $11360,5 \mathrm{Ab}$ & 12782,7 \\
$\begin{array}{l}\text { Folhas médias da planta } \\
\text { inteira }\end{array}$ & $3347,7 \mathrm{Ca}$ & $3648,8 \mathrm{Da}$ & $3864,2 \mathrm{Ca}$ & $3802,8 \mathrm{Ca}$ & 3665,9 \\
$\begin{array}{l}\text { Folhas grandes e médias do } \\
\text { terço inferior da planta }\end{array}$ & $7581,0 \mathrm{Bab}$ & $8499,0 \mathrm{Ca}$ & $6480,7 \mathrm{Bb}$ & $4227,0 \mathrm{BCc}$ & 6696,9 \\
$\begin{array}{l}\text { Folhas grandes e médias do } \\
\text { terço médio da planta }\end{array}$ & $7771,5 \mathrm{Ba}$ & $6989,0 \mathrm{BCa}$ & $6825,2 \mathrm{Ba}$ & $5964,0 \mathrm{Ba}$ & 6887,4 \\
$\begin{array}{l}\text { Folhas grandes e médias do } \\
\text { terço superior da planta }\end{array}$ & $7163,0 \mathrm{Ba}$ & $6168,3 \mathrm{Ba}$ & $5546,8 \mathrm{BCa}$ & $5287,5 \mathrm{BCa}$ & 6041,4 \\
\hline \multicolumn{1}{c}{ Média } & 7741,7 & 7633,1 & 6935,6 & 6136,7 & 7111,8 \\
\hline
\end{tabular}

${ }^{1 /}$ Médias seguidas por uma mesma letra maiúscula na coluna e minúscula na linha não diferem entre si, ao nível de $5 \%$ de probabilidade, pelo teste Tukey.

Analisando as formas de amostragem das plantas onde se mensurou folhas grandes e médias dos terços inferior, médio e superior, constatou-se tanto para comprimento da nervura principal quanto para largura das folhas de pinhão manso, que suas médias foram estatisticamente iguais à média da forma de amostragem tida como padrão na primeira, segunda e terceira época de mensuração (Tabela 2 e 3). Para comprimento estas três formas também não diferem da forma de amostragem tida como padrão na quarta época de mensuração.

Entretanto, para largura a forma de amostragem em que se mensuraram folhas grandes e médias do terço inferior da planta $(6,68)$ diferiu-se da forma de amostragem tida como padrão na quarta época $(8,83)$. Esta diferenciação é reflexo da queda das folhas do terço inferior da planta com o passar do tempo (conforme pode ser visto na Tabela 5), apresentando ao final uma média de 22 folhas, o que inviabiliza sua recomendação para mensuração de folhas na cultura do pinhão manso. Por se tratar de uma planta perene, que pode alcançar alturas de até 12 metros, espera-se que com o passar do tempo a planta apresente cada vez mais, menor número de folhas em seu terço inferior, resultando consequentemente numa menor área foliar (Tabela 4). 
Tabela 5. Médias do número de folhas, em seis formas de amostragem das plantas de pinhão manso e quatro épocas de mensuração, na safra 2007, em Gurupi-TO.

\begin{tabular}{lcccccc}
\hline \multirow{2}{*}{ Formas de amostragem das plantas } & \multicolumn{3}{c}{ Época de mensuração } & \multicolumn{3}{c}{$\begin{array}{c}\text { \%́rea foliar em relação } \\
\text { ao tratamento padrão }\end{array}$} \\
\cline { 2 - 7 } & I & II & III & IV & Comprimento & Largura \\
\hline Folhas grandes e médias da planta inteira & 196 & 220 & 264 & 213 & 100 & 100 \\
$\begin{array}{l}\text { Folhas grandes da planta inteira } \\
\text { Folhas médias da planta inteira }\end{array}$ & 89 & 86 & 89 & 75 & 135 & 145 \\
$\begin{array}{l}\text { Folhas grandes e médias do terço inferior } \\
\text { da planta }\end{array}$ & 38 & 41 & 32 & 22 & 100 & 100 \\
$\begin{array}{l}\text { Folhas grandes e médias do terço médio da } \\
\text { planta }\end{array}$ & 76 & 113 & 111 & 104 & 100 & 104 \\
$\begin{array}{l}\text { Folhas grandes e médias do terço superior } \\
\text { da planta }\end{array}$ & 41 & 47 & 80 & 91 & 95 & 96 \\
\hline
\end{tabular}

De acordo com estes resultados e baseado nos dados da Tabela 4, as formas de amostragem que envolve a quantificação das folhas grandes e médias do terço médio e superior das plantas de pinhão manso, são recomendadas para quantificação da área foliar, pois não diferiram estatisticamente da forma de amostragem tida como padrão. Por estes resultados, deve-se optar pela forma mais simples e segura de se estimar a área foliar. Dos dois, é o terço médio aquele que apresenta o maior número de folhas conforme pode ser visto na Tabela 5, resultando numa necessidade maior de tempo para mensurá-las. Com a realização deste trabalho, concluiu que o terço superior torna-se então o mais recomendado, pois apresenta menor número de folhas em relação ao médio e constância no número de folhas da planta durante todo o seu ciclo.

Observando os dados da Tabela 3, nota-se que a quarta época é a mais rigorosa em separar os tratamentos em diferentes grupos estatísticos. Tanto, que é a única a separar as formas de amostragem em que se mensura folhas grandes e médias do terço inferior da forma de amostragem tida como padrão, onde se mensura folhas grandes e médias da planta inteira.

\section{RESUMO}

Este trabalho objetivou determinar o tamanho ideal de folhas e em que local da planta devem ser realizadas medições para a determinação da área foliar total de pinhão manso. $\mathrm{O}$ experimento foi conduzido na Universidade Federal do Tocantins em delineamento inteiramente casualizado, com 24 tratamentos e seis repetições. Para quantificar a área foliar utilizou-se o método baseado nas dimensões comprimento e largura das folhas. Os resultados mostraram que quando apenas folhas pequenas foram amostradas, a área foliar foi subestimada. Por outro lado, quando apenas folhas grandes foram amostradas, houve superestimação da área foliar. A mensuração de folhas grandes e médias no terço médio e superior da planta pode ser utilizada para a determinação da área foliar total. Assim, concluise que a forma de amostragem é influenciada pela época de mensuração; a quarta época de mensuração é a mais indicada para quantificar a largura das folhas de pinhão manso; e o terço superior da planta mostrou ser o melhor local de amostragem para quantificar a área foliar total.

Palavras-chave: Jatropha curcas L., área foliar, metodologia não destrutiva

\section{REFERÊNCIAS}

Avelar, R. C.; Castro, R. P.; Araujo, J. C.; Dourado, D. C.; Junco, B. B.; Marconato, F. E.; Fraga, A. C.; Castro Neto, P. Emergência e mortalidade de brotações de manivas de pinhão manso (Jatropha curcas L.) In: CONGRESSO BRASILEIRO DE PLANTAS OLEAGINOSAS, ÓLEOS, GORDURAS E BIODIESEL. Universidade Federal de Lavras, 3, 2006.

Benincasa, M. M. P. (1988), Análise de crescimento de plantas: noções básicas. Jaboticabal: FUNEP, 42p.

Favarin, J. L.; Dourado Neto, D.; García, A. G.; Villa Nova, N. A.; Favarin, M. G. G. V. (2002), Equações para a estimativa do índice de área foliar do cafeeiro. Pesquisa Agropecuária Brasileira, 37, 769-773.

Heller, J. Physic nut. Jatropha curcas L. PhD Thesis - Institute of Plant Genetic and Crop Plant 
Research, Gatersleben, Germany, and International Plant Genetic Resource Institute, 1996.

Monteiro, J. E. B. A.; Sentelhas, P. C.; Chiavegato, E. J.; Guiselini, C.; Santiago, A. V.; Prela, A. (2005), Estimação da área foliar do algodoeiro por meio de dimensões e massa das folhas. Bragantia, 64, 15-24.

Nunes, C. F.; Pasqual, M.; Favero, A. C.; Oliveira, D. L. Efeito da sacarose no cultivo in vitro de embriões zigóticos de pinhão-manso. In: CONGRESSO BRASILEIRO DE PLANTAS OLEAGINOSAS, ÓLEOS, GORDURAS E BIODIESEL. Universidade Federal de Lavras, 3, 2006.

Oliveira, M. N. S.; Lopes, P. S. N.; Mercadante, M. O.; Oliveira, G. L.; Gusmão, E. (2002),
Medição da área foliar do pequizeiro utilizando a soma da nervura principal dos folíolos. Unimontes Científica, 3, 1-7.

Saturnino, H. M.; Pacheco, D. D.; Kakida, J.; Tominaga, N.; Gonçalves, N. P. (2005), Cultura do pinhão manso. Informe Agropecuário, 26, 44-78.

Severino, L. S.; Cardoso, G. D.; Vale, L. S.; Santos, J. W. (2004), Método para determinação da área foliar da mamoneira. Revista Brasileira de Oleaginosas e Fibrosas, 8, 753-762.

Severino, L. S.; Vale, L. S.; Beltrão, N. E. M. (2007), A simple method for measurement of Jatropha curcas leaf área. Revista brasileira de oleaginosas e fibrosas, 11, 9-14. 